\title{
Pengaruh Suhu terhadap Sifat Mekanik Biomulsa Berbasis Klobot Jagung dan LLDPE
}

\author{
Yurohman $^{\mathrm{a} *}$, M. Dirgantara ${ }^{\mathrm{b}}$, M. Kurniati ${ }^{\mathrm{b}}$ dan O. Ujianto ${ }^{\mathrm{a}}$ \\ ${ }^{a}$ Sentra Teknologi Polimer, Kawasan PUSPIPTEK Tangerang Selatan, 15314, Indonesia \\ ${ }^{b}$ Departemen Fisika, Institut Pertanian Bogor, Bogor 16680, Indonesia \\ *Surel: yurohman@bpt.go.id
}

\section{INFO ARTIKEL}

Diterima 10 Januari 2019

Direvisi 28 Januari 2019

Disetujui 20 November 2019

Nomor Artikel 201908

Halaman 11-14

\section{Kata kunci: \\ LLDPE \\ Mulsa \\ Tear Test \\ Puncture Test \\ Klobot jagung}

\section{Abstract}

Mulch is a crop cover material that is intended to maintain soil moisture and suppress weed growth and disease, making the plants grow well and optimaly. One that affects mulch in its application in the field is the temperature due to solar radiation. In this study mulch was produced based on corn husk and Linear Low Density Polyethylene (LLDPE) with 2 sizes 100 and 200 mesh, with compositions of 5.10 and $15 \%$ by weight. The process of making mulch using Melt Extrusion with operating conditions: $165-180{ }^{\circ} \mathrm{C}$ and $30 \mathrm{rpm}$ and the final process using Calendering. The mulch was then tested for tearing and puncture to see the mechanical resistance when affected by temperature. The temperature variations are 30,40 and $50{ }^{\circ} \mathrm{C}$. The results of this study indicate that the temperature variation of $50{ }^{\circ} \mathrm{C}$ has a significant influence on the mechanical properties of mulch but is still included in the range of mechanical strength of LLDPE plastic. These results show that the biomulsa can withstand the effects of solar radiation.

Keywords: corn husk, LLDPE, mulch, tear test, puncture test

\begin{abstract}
Abstrak
Mulsa merupakan material penutup tanaman budidaya yang dimaksudkan untuk menjaga kelembaban tanah serta menekan pertumbuhan gulma dan penyakit menjadikan tanaman tersebut tumbuh dengan baik dan optimal. Salah satu yang mempengaruhi mulsa dalam aplikasinya dilapangan adalah suhu akibat radiasi matahari. Dalam penelitian ini mulsa diproduksi berbahan dasar klobot jagung dan Linier Low Density Polyethylene (LLDPE) dengan 2 ukuran 100 dan 200 mesh, dengan komposisi 5, 10 dan $15 \%$ berat. Proses pembuatan mulsa menggunakan Melt Extrusion dengan kondisi operasi: $165-180{ }^{\circ} \mathrm{C}$ dan $30 \mathrm{rpm}$ dan proses akhir menggunakan Calendering. Mulsa kemudian di uji sobek dan puncture untuk melihat daya tahan mekanikanya ketika dipengaruhi suhu. Variasi suhu nya adalah 30,40 dan $50{ }^{\circ} \mathrm{C}$. Hasil penelitian ini menunjukan pada variasi suhu $50{ }^{\circ} \mathrm{C}$ memiliki pengaruh yang cukup signifikan terhadap sifat mekanik mulsa akan tetapi masih masuk dalam rentang kekuatan mekanik plastik LLDPE. Hasil tersebut menunjukan biomulsa tersebut dapat bertahan terhadap pengaruh radiasi matahari.
\end{abstract}




\section{PENDAHULUAN}

Mulsa merupakan material penutup tanaman budidaya yang dimaksudkan untuk menjaga kelembaban tanah serta menekan pertumbuhan gulma dan penyakit sehingga membuat tanaman tersebut tumbuh dengan baik dan optimal. Teknologi pemulsaan dapat mencegah evaporasi. [1].

Dalam hal ini air yang menguap dari permukaan tanah akan ditahan oleh bahan mulsa dan jatuh kembali ke tanah. Akibatnya lahan yang ditanami tidak akan kekurangan air karena penguapan air ke udara hanya terjadi melalui proses transpirasi.

Ada dua jenis mulsa berdasarkan bahan, yakni mulsa organik yaitu mulsa yang berasal dari bahan organik sisa tanaman dan mulsa anorganik yaitu mulsa seperti contohnya mulsa sintetis dari bahan plastik [2]. Mulsa organik seperti mulsa jerami dimanfaatkan pada daerah yang dieksploitasi berat karena jerami mudah lapuk dan pelapukan ini dapat mengembalikan kesuburan tanah. Mulsa sintetik seperti mulsa plastik hitam perak (MHP) dan mulsa perak hitam putih (MPHP) juga telah banyak digunakan karena warna perak pada mulsa dapat memantulkan cahaya sehingga proses fotosintesis dapat berjalan maksimum sedangkan warna hitam biasa diletakkan di bagian bawah dan menempel dengan tanah berfungsi untuk menahan sinar matahari serta akan mencegah pertumbuhan gulma dan rumput liar sehingga nutrisi tanah dapat diserap maksimum oleh pohon (penggunaan obat dan pupuk tanah optimal), mempertahankan suhu tanah serta menjaga kelembaban tanah (disaat hujan tanah tidak terlalu becek karena tertutup plastik mulsa, disaat panas kandungan air tidak menguap hilang ke udara [3].

Sifat mekanik merupakan hal yang sangat penting dalam pengaplikasian mulsa di lapangan, dimana mulsa harus tahan sobek dan tidak mudah rusak akibat tusukan. Selain itu pengaplikasian mulsa dilapangan juga dipengaruhi oleh suhu akibat radiasi matahari, dimana suhu dapat mempengaruhi sifat mekanik dari mulsa. Produk penelitian ini menjadi salah satu alternatif bagi penganekaragaman pemanfaatan dari klobot jagung yang belum optimal dan menjadi solusi bagi agroindustri dalam mengatasi permasalahan produk akhir (end use) terutama limbah yang tidak bisa didaur ulang. Penggunaan Linier Low Density Polyethylene (LLDPE) sebagai matriks mulsa bioplastik memiliki keunggulan dapat bersifat tembus cahaya, lentur, kedap air dan mudah dicetak menjadi lembaran-lembaran tipis. Tujuan penelitian membuat material berbahan dasar klobot jagung dan LLDPE menjadi bioplastik, serta memberikan informasi sifat mekanik dan biodegradable bioplastik tersebut untuk digunakan sesuai dengan kemampuan dari bioplastik tersebut.

\section{METODE PERCOBAAN}

\section{Bahan dan Alat}

Bahan yang digunakan dalam penelitian ini adalah klobot jagung bagian tengah dan dalam limbah dari Pasar Induk Kemang, Polietilen jenis LLDPE kualitas teknis, asam oleat (AO) kualitas teknis, gliserol kualitas teknis, Tinuvin T, dan Irganox 1076 .

Alat yang akan digunakan dalam penelitian ini adalah sampel di oven merk WTC Binder, disk milling untuk mengggiling sampel, untuk mencari memilih ukuran sampel menggunakan ayakan 100 mesh Retsch, untuk mencetak mulsa menggunakan Single Screw Extruder Collin E 30 M, timbangan, untuk karakterisasi sobek dan puncture sampel mulsa menggunakan Universal Testing Machine (UTM) Shimadzu AG-X Plus $50 \mathrm{KN}$ dan dan untuk mencetak sampel uji sobek menggunakan Puncher Mitutoyo.

\section{Metode}

Preparasi awal adalah preparasi klobot jagung. Klobot jagung lapisan ke 4 sampai dengan lapisan ke \pm 15 dibersihkan. Setelah dibersihkan klobot jagung dicacah menggunakan hummer yang selanjutnya dikeringkan menggunakan oven sampai kadar air $10 \%$. Setelah pengeringan klobot jagung digiling dengan disk mill kemudian diayak menggunakan saringan lolos 100 mesh.

Produksi mulsa dilakukan dengan tiga tahap pencampuran. Pertama adalah pencampuran klobot jagung akuades dan giserol. Klobot jagung dan akuades dicampur terlebih dahulu sampai kadar air 25\%, setelah itu dicampur dengan $10 \%$ glyserol kemudian didiamkan selama 2 minggu. Kedua adalah pencampuran LLDPE, AO, Tinuvin P, dan Irganox 1076. LLDPE ditambah $0.2 \%$ Irganox 1076 dengan pencampuran kering kemudian ditambahkan $1 \%$ Tinuvin $\mathrm{T}$ dan $2 \%$ AO [4]. Ketiga adalah pencampuran total dimana campuran pertama dan kedua dicampur dengan variasi 5, 10, 15 (\%bb) campuran pertama. Selanjutanya 5\% campuran pertama disebut M1-05, $10 \%$ campuran pertama disebut M1-10, 15\% campuran pertama disebut M1-15. Pencampuran menggunakan alat ekstrusi pada suhu $\mathrm{T}_{1}=165{ }^{\circ} \mathrm{C}$, $\mathrm{T}_{2}=170{ }^{\circ} \mathrm{C}, \mathrm{T}_{3}=170{ }^{\circ} \mathrm{C}, \mathrm{T}_{4}=175{ }^{\circ} \mathrm{C}, \mathrm{T}_{5}=175^{\circ} \mathrm{C}$ dan $\mathrm{T}_{6}=180{ }^{\circ} \mathrm{C}$ dengan kecepatan putar $30 \mathrm{rpm}$. Hasil ekstrusi kemudian dicetak dengan menggunakan alat calandering dengan lebar $25 \mathrm{~cm}$.

Mulsa kemudian diuji sobek dengan standar ASTM D1004 [5] dan diuji tusukan dengan standar ASTM D4833 [6]. Salah satu sampel dari hasil uji sobek kemudian diberikan pengaruh suhu dengan variasi $30{ }^{\circ} \mathrm{C}, \quad 40{ }^{\circ} \mathrm{C}$ dan $50{ }^{\circ} \mathrm{C}$ untuk melihat pengaruh suhu terhadap sifat mekanik mulsa tersebut. 


\section{HASIL DAN PEMBAHASAN}

Pengujian sifat mekanik yang dilakukan pada penelitian ini adalah uji sobek dan uji tusukan. Uji sobek dilakukan dengan standar ASTM D1004 dengan kecepatan $51 \mathrm{~mm} /$ menit, kelembaman $55 \%$ dan suhu $21,6{ }^{\circ} \mathrm{C}$. Hasil uji sobek dapat dilihat pada Gambar1 dan Tabel 1.

\section{Uji Sobek Mulsa}

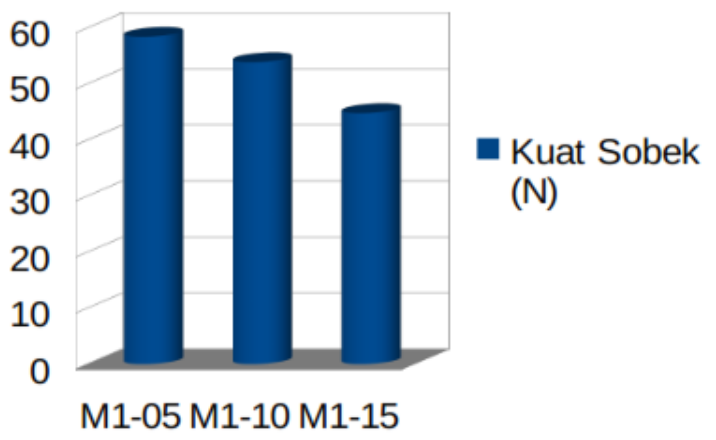

Gambar 1. Uji sobek biomulsa.

Tabel 1. Uji sobek biomulsa.

\begin{tabular}{cc}
\hline Mulsa & Kuat Sobek $(\mathbf{N})$ \\
\hline M1-05 & $\mathbf{5 8 , 3 9 8}$ \\
M1-10 & 53,874 \\
M1-15 & 44,767 \\
\hline
\end{tabular}

Dari hasil tersebut terlihat bahwa penambahan klobot jagung mengakibatkan penuruan kuat sobek dari biomulsa tersebut. Penurunan tersebut diakibatkan perbedaan sifat antara klobot jagung dan LLDPE, dimana klobot jagung cenderung bersifat polar dan LLDPE non polar sesuai dengan penelitian Wu 2014 [7]. Penggunaan asam oleat untuk merekatkan kedua material tersebut masih belum maksimal dimana terjadi penurunan kuat sobek yang cukup signifikan saat penambahan klobot jagung.

Pengujian tusukan dilakukan dengan standar ASTM D4833 dengan kondisi suhu $23{ }^{\circ} \mathrm{C}$ dan kelembaman 46,8\% dengan kecepatan $300 \mathrm{~mm} /$ menit. Hasil uji tusukan dapat dilihat pada Tabel 2. Tidak berbeda jauh dengan uji sobek, pengujian tusukan juga memperlihatkan penurunan gaya maksimum yang dapat diterima mulsa akibat penambahan bahan substitusi klobot jagung. Namun pada uji tusukan penurunan kuat tusuk tidak terlalu signifikan dibandingkan dengan uji sobek. Hal ini menunjukan penambahan klobot jagung tidak berpengaruh signifikan pada kuat tusukan. Bahan pemlastis (gliserol) ditambahkan untuk mengurangi kekakuan dari polimer dan meningkatkan fleksibilitas polimer tersebut. Penambahan pelastis dalam jumlah kecil agar tidak melemahkan plastik yang dihasilkan [8].

\section{Uji Puncture Biomulsa}

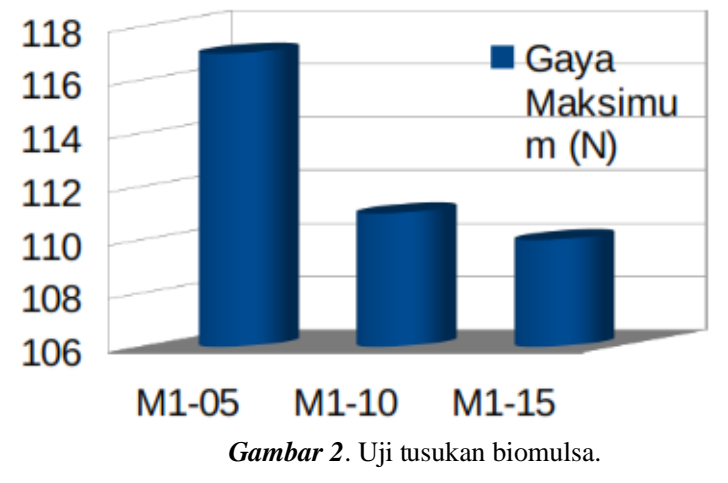

Tabel 2. Uji tusukan biomulsa.

\begin{tabular}{cc}
\hline Mulsa & Gaya Maksimum $(\mathbf{N})$ \\
\hline M1-05 & 117 \\
M1-10 & 111 \\
M1-15 & 110 \\
\hline
\end{tabular}

Dalam aplikasinya di lapangan, mulsa berfungsi untuk menjaga iklim mikro disekitar tanaman tanah [1]. Radiasi matahari jelas dapat menaikan suhu dari mulsa yang tentunya akan terjadi pemuaian dan dapat berpengaruh ke sifat mekanik dari mulsa tersebut. Berdasarkan hasil uji sobek diambil sampel mulsa M1-15 yang memiliki kuat sobek terkecil untuk dilihat pengaruh suhu terhadap kuat sobek mulsa tersebut. Hasil pengaruh suhu terhadap kekuatan sobek dapat dilihat pada Gambar 3 dan Tabel 3.

\section{Pengaruh Suhu terhadap uji sobek}

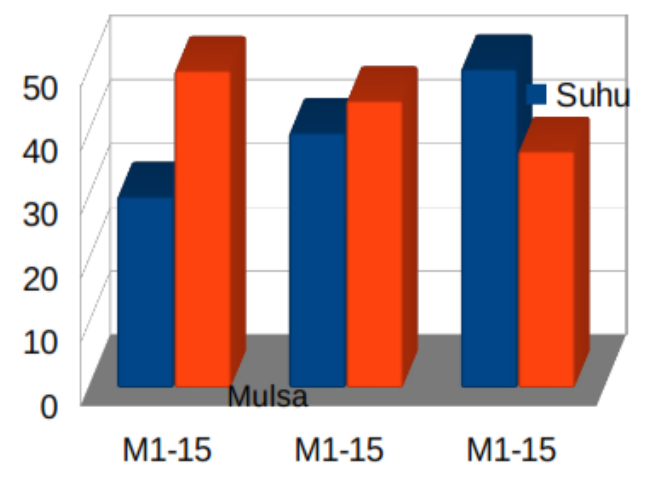

Gambar 3. Pengaruh suhu terhadap kuat sobek mulsa.

Tabel 3. Pengaruh suhu terhadap kuat sobek mulsa.

\begin{tabular}{ccc}
\hline Mulsa & Suhu $\left({ }^{\circ} \mathbf{C}\right)$ & Kuat Sobek $(\mathbf{N})$ \\
\hline M1-15 & 30 & 49,745 \\
M1-15 & 40 & 45,018 \\
M1-15 & 50 & 37,107 \\
\hline
\end{tabular}


Berdasarkan data tersebut, peningkatan suhu sebesar $10{ }^{\circ} \mathrm{C}$ dapat menurunkan kuat sobek dari mulsa. Namun jika dibandingkan dengan tanpa pengaruh suhu (suhu normal), kuat sobek mulsa ketika berada pada suhu $30{ }^{\circ} \mathrm{C}$ dan $40{ }^{\circ} \mathrm{C}$ memiliki nilai yang lebih besar. Suhu permukaan bumi pada siang hari berkisar di $28{ }^{\circ} \mathrm{C}$ dan dapat mencapai $40{ }^{\circ} \mathrm{C}$ saat ekstrim [9]. Suhu dapat mengakibatkan perenggangan material pada mulsa tersebut sehingga dapat meningkatkan sifat elastisitas dari mulsa pada suhu tertentu. Perubahan suhu yang terlalu tinggi dapat mengakibatkan penurunan kuat dan elastisitas dari mulsa. Hasil dari pengujian ini menunjukan bahwa mulsa justru dapat memiliki ketahanan sobek lebih baik ketika diterapkan dilapangan, diaman suhu permukaan bumi akibat radiasi matahari pada siang hari masih berkisar di 28 ${ }^{\circ} \mathrm{C}$.

\section{KESIMPULAN}

Kekuatan sobek dan tusukan menurun dengan penambahan klobot jagung, akan tetapi penurunan tersebut tidak terlalu signifikan pada kekuatan tusukan. Kenaikan suhu dapat mempengaruhi kekuatan sobek dari mulsa diamana peningkatan kekuatan sobek pada suhu $30^{\circ} \mathrm{C}(49 \mathrm{~N})$ dan $40^{\circ} \mathrm{C}(45$ $\mathrm{N})$ dibandingkan dengan suhu normal $(44 \mathrm{~N})$. Mulsa dapat berfungsi baik ketika diterapkan dilapangan dimana peningkatan suhu berkisar di $28{ }^{\circ} \mathrm{C}$ akibat radiasi matahari dapat meningkatkan kuat sobek dari mulsa tersebut.

\section{UCAPAN TERIMA KASIH}

Terima kasih kepada pihak-pihak/ instansi/ lembaga dimana penelitian ini selesai, serta para teman-teman dari Karyawan BTP dan Teman teman dari IPB yang membantu langsung secara signifikan kegiatan penelitian dan penulisan naskah ini.

\section{DAFTAR PUSTAKA}

[1] Kasirajan, Subrahmaniyam M. Ngouajio. Polyethylene and biodegradable mulches for agricultural application: a review. Springer Agronomi, Sustainable. 32:501-529.2012.

[2] William T. 2014. Mulches. Missouri Botanical Garden. http://www.gardeninghelp.org.

[3] Nurdayat, S, T Kemala, Sudirman, Aloma KK. "Pengaruh Penambahan Anti UV Tinuvin 783 Terhadap Karakterisasi Polivinil Klorida". JurnalSains Materi Indonesia. 6 :32-39. 2004.

[4] Abdurahman."Teknik Pemberian Pupuk Organik dan mulsa pada Budidaya Mentimun Jepang". Buletin Teknik Pertanian 10 (2):53-56. 2005.

[5] Standard Test Method for Tear Resistance (Graves Tear) of Plastic Film and Sheeting ASTM D1004-2013.
[6] Standard Test Method for Index Puncture Resistance of Geomembranes and Related Products ASTM D4833 / D 4833 M-07-2013.

[7] Wu,Chin-San. Preparation and characterization of polyhydroxyalkanoate bioplastic-based green renewable composite from rice husk. Journal Polymer Enviromental. 22:384-392. 2014.

[8] Zulferiyenni, Marmiza, Erli Novida S. "Pengaruh konsentrasi gliserol dan tapioca terhadap karakteristik biodegradable film berbasis ampas rumput laut Eucheuma cottonii”.Jurnal Teknologi dan Industri Hasil Pertanian. 19 (3) : 257273, 2014.

[9] Purwantara, Suhardi. Studi temperatur udara terkini di wilayah Jawa Tengah dan DIY. Informasi. 37(2): 166-179. 2011. 